\title{
Erratum to: Lysinibacillus endophyticus sp. nov., an indole- 3 -acetic acid producing endophytic bacterium isolated from corn root (Zea mays cv. Xinken-5)
}

\author{
Jiang Yu $\cdot$ Xuejiao Guan • Chongxi Liu • \\ Wensheng Xiang $\cdot$ Zhenhua Yu $\cdot$ Xiaobing Liu \\ Guanghua Wang
}

Published online: 30 September 2016

(C) Springer International Publishing Switzerland 2016

Erratum to: Antonie van Leeuwenhoek (2016) 109: 1337-1344

DOI 10.1007/s10482-016-0732-3

Subsequent to the publication of the above paper, it has been noticed that the citation given for the Ahmed et al. (2014) reference is incorrect. The correct citation details are as follows:

Ahmed I, Sin Y, Paek J, Ehsan M, Hayat R, Iqbal M, Chang YH (2014) Description of Lysinibacillus pakistanensis. Int J Agri Biol 16:447-450.

The online version of the original article can be found under doi:10.1007/s10482-016-0732-3.

J. Yu $\cdot$ Z. Yu $\cdot$ X. Liu $\cdot$ G. Wang $(\bowtie)$

Key Laboratory of Mollisols Agroecology, Northeast Institute of Geography and Agroecology, Chinese Academy of Sciences, Harbin 150081, China e-mail: wanggh@iga.ac.cn

J. $\mathrm{Yu}$

College of Agronomy, Northeast Agricultural University, 150030 Harbin, China

X. Guan · C. Liu · W. Xiang

Key Laboratory of Agriculture Biological Functional Gene of Heilongjiang Provincial Education Committee, Northeast Agricultural University, 150030 Harbin, China 